\title{
Apontamentos sobre Gramsci e sua influência ao Serviço Social no século 21
}

\author{
Angela Vieira Neves \\ Universidade de Brasília (UnB)
}

\section{Apontamentos sobre Gramsci e sua influência ao Serviço Social no século 21}

Resumo: Este artigo tem como objetivo discutir os principais conceitos de Antonio Gramsci e sua influência para o Serviço Social brasileiro no século 21. Chama a atenção para o Serviço Social na atualidade, na construção e afirmação de uma cultura política profissional voltada aos direitos. Conclui, a partir de uma revisão bibliográfica a importância de Gramsci para o Serviço Social no Brasil ao trazer à luz a ideia de que há disputas entre "culturas profissionais", uma cultura política conservadora e outra construída sob a influência da tradição marxista.

Palavras-chave: Hegemonia. Projeto Político. Cultura Profissional. Ético-Político.

\section{Gramsci and his Influence on Social Service in the Twenty-First Century}

Abstract: The purpose of this article is to discuss the main concepts developed by Antonio Gramsci and his influence on Brazilian social service in the twenty-first century. It calls attention to the construction and affirmation of a professional political culture in social service that is focused on rights. It concludes, based on a bibliographic review, that Gramscian thinking is important to social service in Brazil by bringing to light the idea that there are disputes between "professional cultures", a conservative political culture and another constructed under the influence of the Marxist tradition.

Keywords: Hegemony. Political Project. Professional Culture. Political-Ethics. 


\section{Introdução}

Gramsci tinha como proposta a análise do Estado e uma de suas maiores contribuições se deu com a ampliação do conceito de Estado ao incluir a sociedade civil como aparelho privado de hegemonia, definição muito comum entre governantes, intelectuais e nas práticas políticas do Estado, da sociedade e dos partidos. Outro conceito também fundamental para entender o pensador italiano é a dimensão ético-política de catarse. É a partir destes conceitos gramscianos que vamos refletir sobre o Serviço Social no século 21, lançando um olhar não ortodoxo e mecanicista, mas dialético, crítico, que impactou esta profissão nos anos 1980 e que culminou em análises fundamentais para o fortalecimento do Serviço Social crítico, no século 21.

\section{Gramsci e seus primeiros interlocutores: diálogos fecundos}

A obra de Gramsci foi toda feita na prisão. Seus primeiros escritos datam de 1948, mas a maior parte do seu pensamento foi divulgada post mortem, os chamados Cadernos do Cárcere, com 2.500 páginas, e as notas (Miscelâneas) que não foram revisadas. Iniciou seus escritos em 1929, tendo como principal questão a relação entre cultura, política e filosofia. Ele dialoga com seus colegas do Partido Comunista, no contexto do marxismo clássico, chamando a atenção para um grande problema: por que os intelectuais estão distantes das massas? Como fazer as massas terem poder de decisão na política?

A partir desse questionamento, dialoga não só com os marxistas, mas também critica Mussolini e a Igreja Católica. Nesse sentido, Gramsci vai pensar a concepção dialética da história mostrando os erros metodológicos do Partido para que a classe operária pudesse chegar ao poder com o objetivo de derrubar o Estado burguês. Nesse ponto Gramsci não discordava de Marx: o Estado era um Estado de classes, o qual deveria ser derrubado. Ou seja, ele também queria uma sociedade sem classes antagônicas e sem um Estado burguês: "para Gramsci essa extinção do Estado significa o desaparecimento progressivo dos mecanismos de coerção, ou seja, a reabsorção da sociedade política na sociedade civil" (COUTINHO, 1989, p. 83).

Porém, seu caminho para o chamado socialismo aconteceria com a democracia, como bem afirmou Coutinho (1989, p. 85): "o socialismo vitorioso não poderá consolidar sua vitória e conduzir a humanidade no sentido da extinção do Estado se não tiver realizado integralmente a democracia". Essa questão rebatia diretamente em três questões: crítica ao mecanicismo; ao reducionismo econômico; ao fatalismo e evolucionismo e ao economicismo vulgar. O ponto de reflexão estava centrado na relação entre o materialismo idealista e o materialismo histórico, no qual Gramsci demarca diferenças ao romper com as tendências mecanicistas do seu partido (PCI), que concebia o poder como um lugar coisificado, tomado pelo Estado. Segundo Coutinho (1989, p. 31), "o Maximalismo é uma concepção fatalista e mecanicista da doutrina de Marx [...]. É inelutável que o proletariado vença (diz o Maximalismo). É inútil que a gente se mova: para que se mover e lutar, se a vitória é fatal e inelutável? E um maximalista pode estar [...] também no Partido Comunista".

Na concepção de Gramsci, poder não era uma coisa a ser tomada, mas um conjunto de relações sociais, um processo longo e gradual de uma reforma moral e intelectual das classes subalternas. Chama a atenção para a ortodoxia que, conforme destaca, "não deve ser buscada neste ou naquele seguidor da filosofia da práxis, nesta ou naquela tendência ligada a correntes estranhas à doutrina original, mas no conceito fundamental de que a filosofia da práxis basta a si mesma" (GRAMSCI, 2004, p. 152, v. 1). Gramsci elabora conceitos que ampliam a concepção de Marx, já que a contribuição do pensador italiano se deu no terreno da socialização da política sem deixar de lado os determinantes econômicos. Ele não era um politicista, ${ }^{1}$ nem tampouco um reformista: "para compreender o pensamento de Gramsci, em suas implicações de natureza teórico-prática, é fundamental tomá-lo como um pensador marxista" (SIMIONATTO, 1995, p. 35).

Gramsci também inova ao conceituar o Estado como ampliado, incluindo a sociedade civil como terreno da política da superestrutura. Ele foi além de Marx, para quem o Estado era um instrumento de dominação e coerção das classes no campo da estrutura.

\section{Principais conceitos em Gramsci: hegemonia e política}

Vamos destacar alguns conceitos que influenciaram a sociedade brasileira e o Serviço Social, entre eles, o de hegemonia que, para Gramsci, é orgânica e aparece como uma resposta para a sociedade, a economia e a política. É uma concepção de mundo, um objeto de consentimento que oferece condições de reconhecimento, transcende interesses e se faz com a participação ativa dos sujeitos políticos. A conquista da hegemonia se dá antes da tomada do poder e se fundamenta pelo consentimento, pela direção político-ideológica, pela persuasão 
permanente e pela batalha cultural. A reforma intelectual é a condição para a conquista da hegemonia, é o caminho para a formação da consciência de classe.

A luta pela hegemonia, uma batalha de ideias, de visão de mundo, de ideologia e de projetos políticos em disputa, assume uma importância central na luta pelo poder do Estado e em sua conquista. Pode ser um consentimento ativo não só no discurso, mas, principalmente, na ação política, é, portanto, um processo pedagógico. É importante salientar que hegemonia não pode ser confundida com dominação; hegemonia representa uma direção, conquista, luta, guerra de posição. Gramsci (2002, p. 262, v. 3), diferencia o Ocidente (guerra de posição) do Oriente que é uma guerra de movimento, ataque do Estado de assalto coercitivamente pela força:

No Oriente, o Estado era tudo, a sociedade civil era primitiva e gelatinosa; no Ocidente, havia entre o Estado e a sociedade civil uma justa relação e, ao oscilar o Estado podia-se imediatamente reconhecer uma robusta estatura da sociedade civil. O Estado era apenas uma trincheira avançada, por trás da qual se situava uma robusta cadeia de fortalezas e casamatas; em média diversa de Estado para Estado, é claro, mas exatamente isto exigia um acurado reconhecimento de caráter nacional.

Gramsci não nega que, em determinados momentos, é preciso a força, mas é fundamental a guerra de posição, marcar posição na luta para conquistar seus direitos. A hegemonia é muito mais que um conteúdo, é um procedimento, um projeto de construção de uma nova sociedade externa ao Estado, devendo o exercício do poder ser um processo pedagógico. O conceito de hegemonia reúne as exigências de caráter nacional.

A inovação de Gramsci é pertinente porque amplia o conceito de política antes restrita ao Estado, as suas práticas instituições, para uma política que inclui a sociedade civil. A política está em toda a parte e há, especificamente, duas: a grande e a pequena:

A grande política (alta política) - pequena política (política do dia a dia, política parlamentar, de corredor, de intrigas). A grande política corresponde às questões ligadas à fundação de novos Estados. A pequena política corresponde às questões parciais e cotidianas que se apresentam no interior da estrutura já estabelecida em decorrência de lutas pela predominância entre diversas frações de uma mesma classe política (GRAMSCI, 2002, p. 21, v. 3).

Associado ao conceito de política, Gramsci apresenta o conceito de catarse: para superar a classe hegemônica deve romper com interesses corporativistas e privados elevando-se para uma dimensão "éticopolítica" na busca de uma classe nacional, universal. Essa elevação de uma concepção de mundo de vida superior é também econômica. Há uma concepção de transformação social de construção histórica, na busca da totalidade como um processo construído.

O fato da hegemonia pressupõe, indubitavelmente, que sejam levados em conta os interesses e as tendências dos grupos sobre os quais a hegemonia é exercida, que se forme certo equilíbrio de compromisso, isto é, que o grupo dirigente faça sacrifícios de ordem econômico-corporativa; mas também é indubitável que tais sacrifícios e tal compromisso não podem envolver o essencial, dado que, se a hegemonia é ético-política, não pode deixar de ser também econômica, não pode deixar de ter seu fundamento na função decisiva que o grupo dirigente exerce no núcleo decisivo da atividade econômica. (GRAMSCI, 2002, p. 48, v. 3).

A dimensão ético-política aconteceria como revolução, uma reforma moral e intelectual das classes subalternas sem a qual não conseguiriam construir uma consciência de classe para si, reproduzindo a ideologia do partido ou a ideologia do Estado. Assim, a construção de uma consciência de classe se daria pelas práticas democráticas como um processo construído pelos sujeitos políticos e não como massa de manobra, contrariamente à vanguarda do partido que desejava excluir as massas do processo de decisão da política. Este foi o grande ineditismo de Gramsci e suas críticas ao partido e aos colegas marxistas. O Estado ampliado se daria com a inclusão de uma sociedade civil que não era a sociedade burguesa. Existia uma sociedade civil que Gramsci identificou nos conselhos de fábricas, na organização coletiva da classe operária na luta e pelos seus direitos. A sociedade civil seria os organismos privados de hegemonia, os quais marcavam posição, lutavam e buscavam a conquista de seus direitos por meio de uma concepção de mundo e um projeto político que direcionavam sua ação. Nessas trincheiras, há uma crise de hegemonia que representa um alto grau de participação política em que as classes se tornam sujeitos políticos formando uma classe nacional e universal. Para Gramsci, a luta pela constituinte é necessária para conquistar posições na luta pela hegemonia da classe operária. 
A ideia de se construir uma Nova Cultura põe fim à divisão entre governantes e governados, a reforma intelectual é a condição para a hegemonia, caminho da cultura e da política, é sinônimo de transformação social e histórica. No contexto do Risorgimento, na Itália do século 19, Gramsci questiona a revolução passiva ou revolução pelo alto em que o poder permanece no Estado e exclui a participação do povo. Ressalta a formação de uma elite de homens de gabinete separando a cultura (elitistas) do povo num corporativismo autônomo da realidade. Para Gramsci, a aliança entre camponeses e operários é condição de vitória da revolução proletária. Sem uma nova cultura, as classes subalternas continuam subjugadas à hegemonia das classes dominantes, donde sua crítica a Sorel, que buscava uma reforma intelectual e moral do povo francês pelas altas classes da cultura que tinha para o povo um programa particular:

esse Estado ético ou sociedade civil significariam esta ‘imagem' de Estado sem Estado estava presente nos maiores cientistas políticos da política e do direito, na medida em que situavam no terreno da pura ciência (= pura utopia), enquanto baseada no pressuposto de que todos os homens são realmente iguais e, portanto, igualmente razoáveis e morais, isto é, passíveis de aceitar a lei espontaneamente, livremente, e não por coerção, como coisa imposta por outra classe, como coisa externa à consciência (GRAMSCI, 2002, p. 245, v. 3).

Desse modo, a universalidade do pensamento de Gramsci se dá em três aspectos: pela teoria do Estado ampliado; pela teoria processual e molecular da revolução socialista e guerra de posição; e pela superação do marxismo clássico.

\section{Influência de Gramsci no Brasil e no Serviço Social}

A influência de Gramsci no Serviço Social foi debatida por vários pensadores brasileiros ${ }^{2}$ nos anos 19701980. Pensar Gramsci e sua influência é trazer para o cerne do debate dois conceitos caros ao Serviço Social brasileiro e presente hoje no século 21: hegemonia e projeto político, conceitos que mudaram a análise da intervenção profissional entendida, a partir de agora, como práxis, como mediação. O projeto ético-político ${ }^{3}$ visa à superação dos aspectos corporativos, egoísticos e passionais para elevação de uma análise universal. O projeto éticopolítico profissional, que faz parte de projetos societários que expressam interesses gerais, deve ser entendido como um conjunto de valores e concepções éticas e políticas norteadoras das práxis profissionais, como uma projeção coletiva de determinado grupo social (BRAZ, 2004), nesse caso, dos assistentes sociais.

O Serviço Social aparece no contexto do final dos anos de 1980 e início de 1990 com uma nova proposta que já vinha tendo amadurecimento e acúmulo substancial de conquistas nos campos da produção acadêmica, da prática e das organizações profissionais (IAMAMOTO, 1996). É bom lembrar que com o Movimento de Reconceituação, na década de 1960, o Serviço Social começa o diálogo com a teoria social crítica, iniciando o processo de ruptura do Serviço Social conservador e de renovação de seu conteúdo teórico-filosófico e metodológico. No entanto, essa aproximação se deu com leituras de intérpretes de Marx, resultando em uma interpretação equivocada e vulgar do pensamento marxiano. Ainda assim esse processo representou a possibilidade de construção de uma proposta alternativa do Serviço Social ao conservadorismo, ruptura que só se efeti-

Na concepção de Gramsci, poder não era uma coisa a ser tomada, mas um conjunto de relações sociais, um processo longo e gradual de uma reforma moral e intelectual das classes subalternas. vou nos anos de 1980 quando todo esse processo resultou na construção de uma nova proposta expressa pelo projeto ético-político da profissão, marcando a possibilidade de reafirmação dos direitos e construção de uma nova práxis profissional pautada em uma visão da teoria social crítica. O patrimônio cultural e profissional do Serviço Social, após sua reconceituação, se deu significativamente com a materialização do projeto ético-político que sustenta ações, práticas profissionais e uma direção político-ideológica para o Serviço Social crítico. Isso se deu no Brasil com a influência de Gramsci, nos anos 1980, com o processo de redemocratização e, principalmente, com autores que o recuperaram com diferentes e importantes análises como Vicente de Paula Faleiros, ${ }^{4}$ Marina Maciel, Franci Gomes e Alba Pinto Carvalho, que inauguraram um debate fecundo no processo de intenção de ruptura (NETTO, 2005), fundamental para orientação das práticas profissionais à luz de uma tradição marxista-gramsciana. 
E qual a contribuição de Gramsci, hoje, para pensar o Serviço Social crítico? Estamos nos apropriando de Gramsci para fortalecer nosso projeto profissional ético-político? Importante destacar que o debate sobre Gramsci atualmente tem outra concepção, deve ser profundamente recuperado e debatido no âmbito do Serviço Social, visto que há usos e abusos dos termos ético-político, projeto politico e democracia, como supostos para a consolidação de um profissional voltado ao direito, ou seja, que reforça a cultura dos direitos. Hoje, não temos mais uma intenção de ruptura ${ }^{5}$ com o conservadorismo, o Serviço Social brasileiro realmente rompe com essa concepção e tem em Gramsci uma concepção importante para direcionar as práticas profissionais rompendo com o mecanicismo, o voluntarismo, com o messianismo presente nas práticas e análises marxistas que foram enviesadas por diferentes tradições e orientações. Como afirma Braz e Teixeira (2009, p. 193), "a democracia é um pressuposto para a própria existência do projeto ético-político".

\section{Considerações finais}

A influência de Gramsci para o Serviço Social deve ser aprofundada a partir de alguns elementos históricos presentes na profissão. Destacamos algumas pistas ou tendências dessa influência com a ruptura ou construção de uma nova lógica profissional pautada na cultura de direitos. A influência de Gramsci, a partir da categoria hegemonia, traz luz à ideia de que há disputas entre culturas profissionais, uma cultura política conservadora e outra construída após a influência da tradição marxista, uma cultura política profissional voltada à lógica dos direitos.

Há uma tendência de afirmar uma disputa entre projetos políticos antagônicos na sociedade capitalista e na realidade brasileira. A prática, a partir da influência de Gramsci, é compreendida como filosofia da práxis, como contradição historicamente determinada. A dimensão política, que se diferencia de uma lógica partidarizada, faz com que a dimensão política, pedagógica, educativa e ideológica de Gramsci ganhe força na construção do Serviço Social crítico. Além disso, a dimensão ético-política revela a importância de fortalecer interesses públicos coletivos e universais em detrimento de interesses individuais, o que fortalece o projeto profissional crítico do Serviço Social no século 21. As práticas democráticas devem dar a direção nas ações profissionais ao socializarem a informação, democratizando o acesso aos direitos na ruptura com o moralismo da ação, com as concepções ortodoxas e mecanicistas, principalmente para a construção de uma nova imagem ao Serviço Social. Para ser crítico é preciso inovar na ação, criar, propor alternativas mediadas por respostas concretas à realidade brasileira, ou corremos o risco de cair na doutrinação ao invés de promover emancipação e crítica à sociedade.

Em suma, sob a influência de Gramsci avançamos nas lutas profissionais, nas disputas entre projetos e culturas políticas profissionais ao fortalecer práticas democráticas, pautadas na direção de um projeto político profissional ético-político, portanto universal, baseado nas coletividades, nos interesses públicos e não mais em ações individuais, particulares e conservadoras. Reler Gramsci é fundamental, mas nunca como uma bíblia, pois é preciso retomá-lo. Está posto o desafio.

\section{Referências}

BRAZ, M. O governo Lula e o projeto ético-político do Serviço Social. Revista Serviço Social e Sociedade, São Paulo: Cortez, n. 78, 2004. BRAZ, M.; TEIXEIRA, J. B. O projeto ético-político do Serviço Social. Serviço Social: direitos sociais e competências profissionais. CFESS/ABEPSS/CEAD/UnB, DF, 2009.

COUTINHO, C. N. Gramsci. Um estudo sobre o pensamento político. Rio de Janeiro: Campus, 1989.

GRAMSCI, A. Cadernos do cárcere. Rio de Janeiro: Civilização Brasileira, v. 3, 2002.

. Cadernos do cárcere. Rio de Janeiro: Civilização Brasileira, v. 1, 2004.

IAMAMOTO, M. V. Renovação e conservadorismo no Serviço Social. São Paulo: Cortez, 1996.

NETTO, J. P. Ditadura e Serviço Social: uma análise do Serviço Social no Brasil pós-64. São Paulo: Cortez, 2005.

SIMIONATTO, I. Gramsci: sua teoria, incidência no Brasil, influência no Serviço Social. São Paulo: Cortez; Santa Catarina: UFSC, 1995.

\section{Notas}

1 Para Coutinho (1989), Gramsci não é um politólogo (e muito menos um politólogo com desvios politicistas), mas sim um crítico da política.

2 Simionatto (1995) promove ampla discussão dos autores e de concepções que influenciaram o Serviço Social no Brasil com a entrada de Gramsci, a partir dos anos 1970, principalmente nas décadas de 1980 e 1990. 
3 O projeto ético-político profissional é pautado em três pilares: o Código de Ética, de 1993; a Lei 8.662/93, de regulamentação da profissão; e as diretrizes curriculares dos cursos de Serviço Social, de 1996.

4 Simionatto (1995) discute com profundidade cada autor mencionado a partir dos aportes teóricos gramscianos que influenciaram o Serviço Social brasileiro.

5 Segundo Netto (2005), a aproximação com o marxismo se deu com a intenção de ruptura tendo em Yamamoto a consolidação e o espraiamento na academia do debate marxiano.

\section{Angela Vieira Neves}

angelaneves@unb.br

Doutora em Ciências Sociais pela Universidade Estadual de Campinas (UNICAMP)

Professora do Programa de Pós-Graduação em Política Social e do Departamento de Serviço Social da Universidade de Brasília (UnB)

\section{UnB}

Campus Universitário Darcy Ribeiro

Brasília - Distrito Federal - Brasil

CEP: 70910-900 